\title{
Playback of felid growls mitigates crop-raiding by elephants Elephas maximus in southern India
}

\author{
Vivek Thuppil and Richard G. Coss
}

\begin{abstract}
We attempted to deter crop-raiding elephants Elephas maximus by using playbacks of threatening vocalizations such as felid growls and human shouts. For this purpose, we tested two sound-playback systems in southern India: a wireless, active infrared beam-triggered system to explore the effects of night-time uncertainty in elephants' assessment of predatory threats, and a passive infrared motion detector-triggered system for closer-range playbacks. Using the first system, we deterred $90 \%$ of crop-raiding attempts using tiger Panthera tigris growls, $72.7 \%$ using leopard Panthera pardus growls, and $57.1 \%$ using human shouts, with no statistically significant difference among the three sounds. Using the second system, playbacks of tiger and lion Panthera leo growls deterred 100 and $83.3 \%$ of crop-raiding attempts, respectively, with no statistically reliable difference between the two, although video evidence indicated that elephants were more fearful of tiger growls. Our results indicate that playbacks of threatening sounds can be effective in mitigating human-elephant conflict, particularly in bolstering existing deterrent methods.
\end{abstract}

Keywords Antipredator behaviour, Asian elephant, Bandipur, crop-raiding, Elephas maximus, human-elephant conflict, Nilgiri Biosphere Reserve

This paper contains supplementary material that can be found online at http://journals.cambridge.org

\section{Introduction}

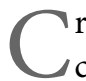
rop-raiding is the most costly form of human-elephant conflict, both economically and in terms of loss of life, throughout elephant-range countries in Asia and Africa (Sukumar, 2003). Rural communities may regard elephants as agricultural pests and an impediment to a better standard of living (Bandara \& Tisdell, 2003), and many farmers harvest crops prematurely and accept financial losses rather than risking their entire harvest (Madhusudan, 2003).

VIVEK THUPPIL (Corresponding author) Animal Behavior Graduate Group, University of California, Davis, One Shields Ave., Davis, CA 95616, USA E-mail vivek.thuppil@nottingham.edu.my

RiChARD G. Coss Department of Psychology, University of California, Davis, USA

${ }^{*}$ Currently at: School of Psychology, University of Nottingham Malaysia Campus, Jalan Broga, 43500 Semenyih, Selangor, Malaysia

Received 27 January 2014. Revision requested 1 May 2014.

Accepted 5 August 2014. First published online 18 March 2015.
Human-elephant conflict also results in the deaths of c. 400 people and 100 elephants annually in India alone (Rangarajan et al., 2010). Nonetheless, communities living in close proximity to elephants may be supportive of elephant conservation measures if the authorities address the problems of elephant attacks and economic losses (Bandara \& Tisdell, 2003).

Elephant-proof trenches are commonly used to prevent elephants from entering farms and endangering people (Sukumar, 2003). They have been used to mitigate crop-raiding in elephant-range countries throughout Asia and Africa. However, some environments, such as marshland, are not suitable for the creation of trenches, and trenches are less effective in places with annual rainfall $>120$ $\mathrm{cm}$ because trench walls are then susceptible to mudslides, allowing elephants passage (Sukumar, 2003). Electric fences are also commonly used as barriers, delivering short high-voltage pulses to repel elephants (Sukumar, 2003). However, although they are easier and cheaper to construct than trenches they are also more likely to be damaged by elephants (Sukumar, 2003), a phenomenon we recorded on video.

We investigated the use of playback of provocative sounds to deter crop-raiding Asian elephants Elephas maximus, based on the supposition that threatening vocalizations (e.g. from people or tigers Panthera tigris) would frighten elephants from continuing along a path to engage in crop-raiding. People and tigers have a history of interaction with elephants such that both may be perceived by elephants as threatening (Thuppil \& Coss, 2012). Humans pose a threat to elephants in the context of crop-raiding (Rangarajan et al., 2010), and tigers are known to hunt elephant calves opportunistically (Andheria et al., 2007). Although leopards Panthera pardus and Asian elephants are sympatric, leopards are not known to pose a threat to elephants (Hayward et al., 2006; Kumaraguru et al., 2011).

Phylogenetic, biogeographical and fossil analyses point to southern Asia as the origin of all pantherine cats (Tseng et al., 2013). Fossil evidence indicates that elephants were sympatric with tigers, leopards and Asiatic lions Panthera leo persica in the Indian subcontinent during the Late Pleistocene (Manamendra-Arachchi et al., 2005; Chauhan, 2008). The Asiatic lion now exists only in Gir National Park, in a region where the elephant population became fragmented several thousand years ago and elephants are no longer extant there (Sukumar \& Santiapillai, 1996). In southern Africa lions Panthera leo are known to predate upon African elephants Loxodonta africana, 


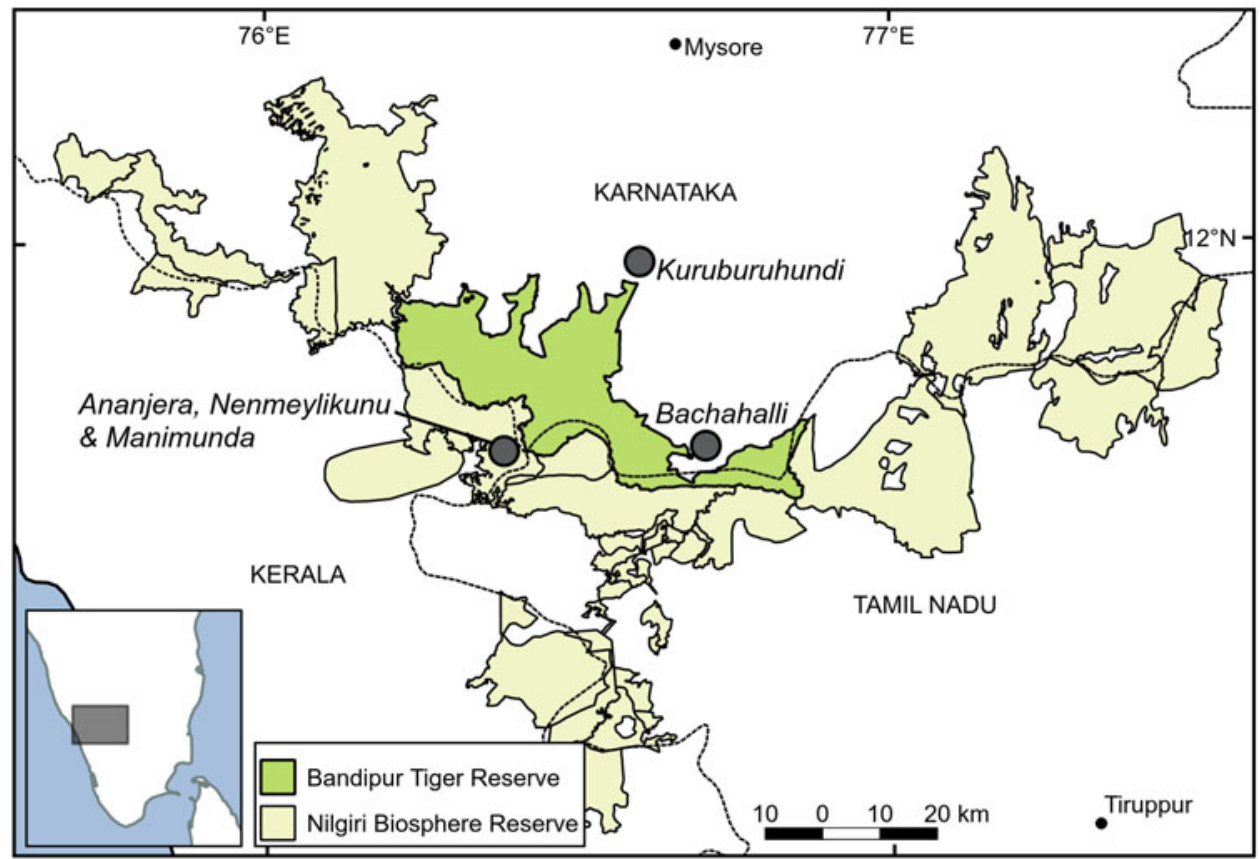

FIG. 1 Locations of the study sites in the vicinity of the Nilgiri Biosphere Reserve in southern India. The rectangle on the inset shows the location of the main map in India. including subadults and adults (Power \& Compion, 2009), and therefore it is reasonable to assume that they would have posed a similar predatory threat to the comparatively smaller Asian elephant when they were sympatric. Thus, the simulated presence of lions in southern India could trigger antipredator behaviour in elephants despite several thousand years of relaxed selection. We hypothesized that elephants would perceive human shouts as more threatening than felid growls, and tiger growls as more threatening than leopard growls. Given that lions were an ancestral predator, playback of lion growls may also be provocative in deterring crop-raiding.

\section{Study area}

The study was conducted at five locations around the Nilgiri Biosphere Reserve $\left(5,520 \mathrm{~km}^{2}\right.$; Fig. 1), a network of protected areas in southern India and one of the most important Asian elephant habitats (Sukumar \& Santiapillai, 1996; Silori \& Mishra, 2001), with more wild Asian elephants than any comparable region (Sukumar \& Santiapillai, 1996; Gubbi, 2009). Agriculture is predominantly rain-fed, and seeding, ploughing, maturing and harvest times are broadly similar across the region, resulting in predictable time-scales of elephant crop-raiding.

The maximum distance between research sites was 45 $\mathrm{km}$, with the closest sites only $1 \mathrm{~km}$ apart, and all sites were susceptible to elephant crop-raiding.

Ananjera, Wayanad District, Kerala The village of Ananjera had one large paddy field planted with rice and bananas and was surrounded by an elephant-proof trench with a $100 \mathrm{~m}$ gap (because of a marsh) on the eastern side. This gap was exploited by crop-raiding elephants. Farmers defended their fields by yelling, shining flashlights, and using slingshots to shoot stones, which were sometimes wrapped in cloth dipped in kerosene and set alight. Despite these efforts there were considerable crop losses to elephants. In the year preceding our study, 2.4 ha of crops were raided by elephants, of which 0.9 ha were completely destroyed.

Nenmeylikunu, Wayanad District, Kerala The village of Nenmeylikunu, $1 \mathrm{~km}$ from Ananjera, also had a large paddy field planted with rice and bananas, which was protected by a trench with a $60 \mathrm{~m}$ gap in a marshy area. The gap was bridged by a rudimentary electric fence, consisting of two live wires with a pulsed $8,000 \mathrm{~V}$ direct current. This fence was broken repeatedly during the year preceding the study, and twice immediately prior to the commencement of the study in 2010; we filmed an additional unsuccessful breakage event subsequently. Elephants destroyed 1.5 ha of cultivated crops during the 2009-2010 monsoon season and 0.12 ha in 2010 prior to the commencement of the study.

Bachahalli, Gundlupet District, Karnataka The village of Bachahalli had no trenches or electric fences to protect against incursion by elephants. Elephants could enter farms from anywhere along the western boundary $(>1$ $\mathrm{km}$ ) of the cultivated area, which spanned $>400$ ha. Generally, incursion was limited to c. 100 ha of crops within $1 \mathrm{~km}$ of the forest boundary. Crops included horse gram, maize and sugarcane. In the year preceding the 
study, local people estimated there were 10-14 crop-raiding events during the harvesting months of November-January. Precise estimates of the area of crops damaged by elephants were unavailable.

Manimunda, Wayanad District, Kerala The village of Manimunda is surrounded by the forests of Wayanad Wildlife Sanctuary. Crops cultivated included rice, bananas, coconuts and areca nuts. The village was surrounded by an elephant-proof trench with two gaps, one on the northern side and the other on the southern side, where a road passes through. Elephants exploited these 4-m-wide gaps to crop-raid. The total cultivated area was c. 43 ha, of which 11 ha, located within c. $600 \mathrm{~m}$ of the two gaps, were particularly vulnerable to damage by elephants. Exact data on the area of cropland damaged in the year preceding the study were unavailable.

Kuruburuhundi, Gundlupet District, Karnataka Crops cultivated in the village of Kuruburuhundi included sugarcane, maize and horse gram, and the crop fields abutted Bandipur Tiger Reserve. There was an electric fence along the border of the Reserve and a trench along most of the border to prevent elephants from leaving the forest. At two locations along this boundary, where a road passed through, there was an electric fence but no trench, and these locations were more susceptible to elephants breaking through. Elephants approached these points along a narrow pathway (maximum width $40 \mathrm{~m}$ ). In the year preceding the study, elephants had broken through the fence at these locations on numerous occasions and damaged crop fields. Data on the extent of cropland damaged were unavailable.

\section{Methods}

\section{Active infrared beam playback system}

This system was designed to determine which playback sounds were most provocative to elephants and mitigated crop-raiding. It explored the effects of night-time uncertainty in elephants' assessment of predatory threats; this uncertainty arose because while the elephants heard the playbacks of threatening sounds, they would not have seen anything and may or may not have received olfactory cues from the environment, depending on the presence or absence of felids at the study sites. Each playback device consisted of a 10-channel mp3 player coupled with a battery-powered $200 \mathrm{~W}$ amplifier and speaker, encased in a waterproof housing, which emitted sound directionally via an acoustic horn at $105 \mathrm{~dB}$ peak sound pressure level 1 $\mathrm{m}$ from the source. This is not excessively loud for a large felid: lions roar at a volume of $114 \mathrm{~dB}$ sound pressure level at $1 \mathrm{~m}$ (McComb et al., 1994).

When elephants tripped a beam from a Takenaka PB-6o TK infrared receiver-transmitter system, a wireless link activated playback of a single sound exemplar selected at random by the mp3 player from 2-3 exemplars of tiger growls, leopard growls or human shouts (Thuppil \& Coss, 2013). The infrared transmitter was aligned to project a pulsed beam c. $60 \mathrm{~m}$ to a receiver. We positioned the beam at a height of $1.85 \mathrm{~m}$ so that it would be intersected by passing elephants but not by humans or other animals.

These sound-playback devices were positioned c. $50 \mathrm{~m}$ from locations where elephants triggered the infrared beams; the elephants heard the playbacks at $60-65 \mathrm{~dB}$ sound pressure level, depending on vegetation cover in the area. This volume is comparable to that at which African elephants heard lion-growl playbacks in a daytime experiment conducted by McComb et al. (2011). Our playbacks were triggered instantaneously when the infrared beam was broken.

The nocturnal behaviour and vocalizations of elephants were recorded by motion-sensitive, high-definition infrared video cameras with microphones (Supplementary Material). Because the system was in continuous operation, the $12 \mathrm{AH}, 12 \mathrm{~V}$ sealed lead-acid batteries for the infrared beam and sound-playback devices required charging every 2-4 days. We used this playback system at Bachahalli during September-December 2009 and October 2010-March 2011, at Ananjera during August 2010-March 2011 and at Nenmeylikunu during October 2010-March 2011.

\section{Passive infrared sensor playback system}

Although the active infrared playback system was effective in deterring crop-raiding, we discovered limitations that made it impractical for broad-scale adoption by local people. These limitations included the expense, complexity and high maintenance required, such as the short battery life and the technical complexities of setting up infrared beams and wireless transmitters. We therefore adapted the system to use inexpensive passive infrared motion detectors, which were mounted on top of the playback devices, equipped with an infrared-transparent Fresnel lens with a detection range of $10-15 \mathrm{~m}$. The devices were modified such that the passive infrared motion sensors were the only part of the system in continuous operation; for the other components, battery power was activated for $30 \mathrm{~s}$, triggered by the motion of an approaching elephant. This modification resulted in a $95 \%$ reduction in power consumption, with a single battery providing 45 days of continuous operation. A drawback of the modification was that there was a c. $4 \mathrm{~s}$ lag between the sensor detecting elephants and the amplifier powering up. 
We re-recorded all the original sound playbacks through vegetation at a distance of $10 \mathrm{~m}$ to capture the effects of attenuation, and played the re-recorded sounds to elephants from a distance of $10 \mathrm{~m}$, to simulate a sound emanation distance of c. $20 \mathrm{~m}$. To this effect, we adjusted the speaker sound intensity to $94 \mathrm{~dB}$ sound pressure level at $1 \mathrm{~m}$ from the source, yielding c. $75 \mathrm{~dB}$ sound pressure level at locations where elephants triggered the devices. This volume was approximately twice as loud as the $60-65 \mathrm{~dB}$ sound intensity produced by the active infrared-beam playback devices. We employed the passive infrared playback systems at Kuruburuhundi during October 2011-March 2012 and at Manimunda during December 2011-March 2012.

\section{Playback sounds}

We recorded the night-time presence of both tigers and leopards on video cameras at the study sites, indicating that the playback of both categories of growls was naturalistic. Our playback growls were recorded by Uma Ramakrishnan from one tiger and one leopard at the Bannerghatta Zoological Park, Bangalore, using a Sennheiser ME 80 directional microphone coupled to a Sony TC-D5 PROII analogue recorder. Both felids were agitated similarly to engender growling: the keeper entered their cages and banged a stick repeatedly (Thuppil \& Coss, 2013). The procedure was not repeated with other individuals because of the potential danger involved. We digitized the recordings in 16-bit mode and $48 \mathrm{kHz}$ sampling frequency for random playback by 10 -channel mp3 players and edited them based on natural growl pauses, creating two exemplars of each felid growl (Thuppil \& Coss, 2013). The exemplars of continuous leopard growls were 9 and $17 \mathrm{~s}$ in duration and of tiger growls 21 and $35 \mathrm{~s}$, reflecting the natural variation in growl expression of these individuals (Thuppil \& Coss, 2013). The active infrared playback system was used to play back tiger and leopard growls at Bachahalli, tiger growls at Ananjera and leopard growls at Nenmeylikunu. The passive infrared system was used to play back tiger growls at Manimunda and Kuruburuhundi.

Villager shouts were naturalistic vocalizations to use, as it is likely that elephants are exposed to angry shouting during crop-raiding forays. Shouting vocalizations of a group of 30 men were recorded at Bachahalli. We asked the men to shout as they would to drive elephants from their farms, and recorded these shouts using a Sony digital recorder. Three exemplars of shouts recorded from this group, edited to provide 93-97 s of continuous shouting, and fading to no sound during the last $20 \mathrm{~s}$, were used in playback. The fading out of the sound was to simulate people moving away from the forest boundary, where the elephants were encountered, and towards the village, where they would raise the alarm about the presence of elephants. The active infrared playback system was used to play human shouts at Ananjera and Bachahalli.

In our passive infrared-based system we used playbacks of African lion growls. These were digitized from MGM movie studio recordings spanning 20 years. The behaviour of these captive lions suggests they were harassed by their trainers to initiate aggressive growling. Unlike the growling of our leopard and tiger exemplars, the lion growls were not continuous, thus requiring the joining of growl segments from the same individuals to create two 25 s sound exemplars. Lion growls were played back at Kuruburuhundi and Manimunda.

We initially considered using a non-threatening control sound, such as repetitive hoots from two interacting brown owls, a frequently heard nocturnal species in the area that poses no threat to elephants, but we did not do so. The farmers with whom we interacted risk their lives regularly to protect their crops, and thus for ethical reasons we decided not to play back sounds that were unlikely to deter elephants.

\section{Results}

The startle response of elephants to playbacks of tiger and leopard growls was almost instantaneous (mean reaction time $490 \mathrm{~ms}$, range $230-820 \mathrm{~ms}, \mathrm{n}=16$ ). When elephants responded behaviourally by vocalizing, they did so shortly after the onset of growl-playback (mean latency $3.6 \mathrm{~s}$, range 1-10 $s, n=11$ ), rendering natural differences in growl duration unimportant, as the elephants vocalized prior to the termination of growling.

Elephants were identified individually by specific morphological differences observed in the high-definition videos. We used elephant crop-raiding attempts, categorized as elephant-nights, as the unit of analysis. Elephant-nights used for analyses could include the same elephant group on different nights or different elephant groups on the same night. When an individual elephant encountered the same playback system repeatedly on the same night, only the final encounter of the playback system was taken into account to determine the success of elephant deterrence.

In instances where more than one elephant encountered a playback system, the response of the leading elephant, either an adult female or an older male in some male-only groups, was considered for behavioural analysis (Thuppil \& Coss, 2013). This response always characterized the overall behaviour of the herd, captured on video. Demographic details of elephant herds encountered during crop-raiding attempts are in Table 1.

We examined the frequency of crop-raiding deterrence with contingency tables. Multinomial log linear analysis with maximum likelihood estimation revealed that, for 41 elephant-nights, playback of tiger and leopard growls and human shouts deterred 90, 72.7 and $57.1 \%$ of crop-raiding 
TABLE 1 Numbers of solitary elephants Elephas maximus and herds that encountered active and passive infrared beam playback systems around the Nilgiri Biosphere Reserve (Fig. 1) in southern India.

\begin{tabular}{|c|c|c|c|c|c|c|c|}
\hline & $\begin{array}{l}\text { Single } \\
\text { male }\end{array}$ & $\begin{array}{l}\text { Single } \\
\text { female }\end{array}$ & $\begin{array}{l}\text { Herd led } \\
\text { by male }\end{array}$ & $\begin{array}{l}\text { Herd led } \\
\text { by female }\end{array}$ & $\begin{array}{l}\text { Herds with }>1 \\
\text { adult (\%) }\end{array}$ & $\begin{array}{l}\text { Herds with non-leading } \\
\text { adult males }(\%)\end{array}$ & $\begin{array}{l}\text { Herds with at least } 1 \\
\text { calf or juvenile (\%) }\end{array}$ \\
\hline \multicolumn{8}{|c|}{ Active infrared beam playback systems at all locations } \\
\hline Human shout & 0 & 2 & 9 & 2 & 6.3 & 0 & 18.2 \\
\hline Leopard growl & 0 & 0 & 3 & 8 & 18.2 & 9.1 & 72.7 \\
\hline Tiger growl & 1 & 3 & 3 & 3 & 16.7 & 16.7 & 50 \\
\hline \multicolumn{8}{|c|}{ Active infrared beam playback systems at Ananjera \& Nenmeylikunu } \\
\hline Human shout & 0 & 2 & 9 & 0 & 0 & 0 & 0 \\
\hline Leopard growl & 0 & 0 & 3 & 0 & 0 & 0 & 0 \\
\hline Tiger growl & 0 & 0 & 3 & 1 & 0 & 0 & 25 \\
\hline \multicolumn{8}{|c|}{ Passive infrared beam playback systems } \\
\hline Tiger growl & 5 & 2 & 0 & 0 & 0 & 0 & 0 \\
\hline Lion growl & 6 & 5 & 1 & 0 & 100 & 100 & 0 \\
\hline
\end{tabular}

TABLE 2 Numbers of crop-raiding attempts by elephants, and the percentage deterred by playbacks of tiger and leopard growls and human shouts on first and subsequent encounters, at the Ananjera and Nenmeylikunu field sites in southern India (Fig. 1).

\begin{tabular}{ll}
\hline Playback & $\begin{array}{l}\text { No. of crop-raiding attempts (\% deterrence) } \\
\text { on first/subsequent encounters }\end{array}$ \\
\hline Tiger growls & $2(100 \%) / 1(50 \%)$ \\
Leopard growls & $1(100 \%) / 2(100 \%)$ \\
Human shouts & $5(83.33 \%) / 1(16.67 \%)$ \\
\hline
\end{tabular}

attempts, respectively. The interaction of playback sounds and crop-raiding frequencies is not significantly different (likelihood ratio $\chi^{2}=3.365, \mathrm{df}=2, \mathrm{P}=0.186$ ).

Repeated encounters with the playback system can lead to habituation and reduce the efficacy of playback as a deterrent. In the neighbouring villages of Ananjera and Nenmeylikunu there was a higher incidence of repeated crop-raiding, predominantly by male elephants (Table 1), and thus a stronger habituation effect. Multinomial loglinear analysis revealed that, in this environment, for 19 elephant-nights, only leopard growls maintained their deterrent properties in subsequent elephant encounters (Table 2). As such, the interaction of the three sound playbacks and frequencies of crop-raiding deterrence was statistically significant (likelihood ratio $\chi^{2}=5.974, \mathrm{df}=2, \mathrm{P}=0.05$ ).

We compared the effects of tiger growls and growls from an unfamiliar large felid, the African lion, using a passive infrared-based playback system at Kuruburuhundi and Manimunda. Demographic details of elephants that encountered these playbacks are provided in Table 1. Multinomial log-linear analysis revealed that, for 19 elephant-nights, tiger and lion-growl playbacks deterred elephants from moving towards crop fields in 100 and $83.3 \%$ of instances, respectively. The interaction of tiger and lion growls and crop-raiding deterrence frequencies is not statistically significant (likelihood ratio $\left.\chi^{2}=1.973, \quad \mathrm{df}=1, \quad \mathrm{P}=0.16\right)$. Data partitioning confirmed that both tiger and lion growls deterred crop-raiding elephants $\left(\chi^{2}=9.704, \mathrm{df}=1, \mathrm{P}=0.002\right.$ and $\chi^{2}=5.824, \mathrm{df}=1, \mathrm{P}=0.016$, respectively).

\section{Discussion}

We found differences in the effectiveness of the two types of sound-playback systems, although both were effective overall in deterring elephant crop-raiding.

\section{Active infrared beam playback system}

Using the active infrared beam playback system, tiger growls deterred crop-raiding on the highest proportion of elephant-nights, although a habituation effect was observed in areas where elephants repeatedly encountered these playback systems. It was interesting to note that even in villages where crop-raiding occurred repeatedly and habituation effects were most evident, the leopard growl maintained its deterrent properties, whereas both tiger growls and human shouts lost their deterrent properties after repeated playbacks. This result is surprising because we had hypothesized that leopard growls would be the least threatening of the three vocalizations. There is evidence to support this hypothesis: our data show that elephants vocalized aggressively in response to leopard growls, whereas they retreated quickly and silently on hearing tiger growls (Thuppil \& Coss, 2013). In addition to vocalizing after hearing leopard growls, elephants tended to linger in the vicinity to investigate the area prior to retreating (Thuppil \& Coss, 2013). This apparently conflicted behaviour indicates that elephants are generally more fearful of encountering a tiger than a leopard (Thuppil \& Coss, 2013).

We surmise that leopard growls may have maintained their crop-raiding deterrence despite repeated exposure as a result of being in proximity to a second deterrent. In Nenmeylikunu the infrared beam used to trigger leopard 
TABLE 3 The sequence of sound-playback exposure and crop-raiding deterrence for a single male elephant at the Ananjera and Nenmeylikunu field sites. Note that the 3 rd tiger growl playback event is the 6th overall playback event (in parenthesis) and the 5 th leopard growl playback event is the 14th overall playback event (in parenthesis). In this table, every encounter with the playback system is considered, rather than just the final encounter of the night, which was the basis of the elephant-night analyses.

\begin{tabular}{llll}
\hline Sequence of sound playback exposure & Tiger growls & Leopard growls & Human shouts \\
\hline 1st event & Yes (1) & Yes (3) & Yes (5) \\
2nd event & Yes (2) & Yes (4) & Yes (8) \\
3rd event & No (6) & Yes (11) & No (9) \\
4th event & No (7) & Yes (13) & No (10) \\
5th event & & Yes (14) & No (12) \\
\hline
\end{tabular}

growls was aligned parallel to an electric fence. Elephants approaching the crop fields from the forest would first trip the beam, triggering playback of leopard growls. If they continued to advance they would encounter an electric fence c. 5 $\mathrm{m}$ ahead.

The electric fence had been broken previously by these same elephants and we captured on video an unsuccessful attempt to break the fence. Thus, the electric fence alone was by no means a forbidding or impenetrable defence. However, the sound-playback system and the electric fence together deterred crop-raiding elephants, even after accounting for the habituating effects of repeated exposure to sound playbacks.

For one large male elephant observed to crop-raid repeatedly, tiger growls and human shouts maintained their efficacy in preventing crop-raiding at Ananjera for only the first two playback exposures. However, at Nenmeylikunu, leopard growls deterred the same elephant in all five trials in which they were used (Table 3). Although this behaviour was observed in only a single individual, such observations of a single individual can be informative (Dukes, 1965) when there are limited opportunities for observing certain behaviours.

The above findings are not surprising in the context of cost-benefit analyses. Crop-raiding is thought to be a component of an elephant's optimal foraging strategy (Sukumar, 1990), based on a cost-benefit calculation. Elephants are drawn to crop fields because people plant crops that are nutritious, digestible, high in energy, and contain low levels of harmful and undesirable secondary compounds (Rode et al., 2006). However, there is a tradeoff as crop-raiding elephants may be harassed and threatened by farmers. This is why elephants tend to crop-raid only when the quality of wild forage declines substantially (Osborn, 2004) or when obtaining reproductive advantage is a necessity (Chiyo \& Cochrane, 2005). Elephants are less likely to crop-raid on nights when there is a full moon, when they can be seen more easily (Gunn et al., 2014), and it is easier to deter elephants from crop-raiding when they are confronted prior to entering farmlands (Sitati et al., 2005). This implies that if the opportunity cost of entering a crop field is sufficiently high, elephants will not crop-raid. This appears to have been the case at Nenmeylikunu, where crop-raiding elephants were faced with the prospect of encountering both a leopard and an electric fence. We surmise that the combination of these two deterrents presented an opportunity cost that the elephants were not willing to pay.

\section{Passive infrared sensor playback system}

Using the passive infrared sensor playback system, both tiger and lion growls were effective in deterring elephants. However, the response of one elephant that encountered playbacks of both tiger and lion growls is informative. The elephant was not deterred from crop-raiding when it first encountered a lion-growl playback but it backed away quickly on hearing a tiger-growl playback on a later date, which suggests that the tiger growl was perceived as more threatening than the lion growl.

From a conservation perspective, absolute deterrence of crop-raiding is essential. Even one or two crop-raiding forays can be devastating in terms of overall crop loss and can result in human-elephant conflict. Techniques aimed at mitigating crop-raiding must ensure maximum deterrence at all vulnerable sites in a region to avoid simply shifting the problem from one village to the next. Although this does not always occur (King et al., 2009), we observed crop-raiding elephants proceeding immediately to another nearby crop-raiding location when deterred from one site, and this pattern of behaviour supports the assumption that elephants perform a cost-benefit analysis and will choose the path of least resistance rather than persevere at a single location. For conservation applications where felid growls are used to deter crop-raiding Asian elephants, we conclude that tiger growls are the most effective vocalization, and recommend that they be used in conjunction with other deterrents, such as electric fences or elephantproof trenches. We are in the process of identifying suitable locations where the low-cost passive infrared-triggered devices are likely to have maximum deterrence. We will then work with conservation organizations to implement the devices on a large scale. 


\section{Acknowledgements}

This research was supported by the U.S. Fish and Wildlife Service Asian Elephant Conservation Fund and the Rufford Small Grants Foundation. We thank R. Johnson, S. Joshi and A. Pittet for providing electronic engineering assistance. We thank R. Sukumar for hosting us at the Field Research Station, Masinagudi. We thank the forest departments of Karnataka and Kerala for providing us with research permissions. We thank D. Thiwary for valuable assistance in the field, and our field assistants on this project, Arun, Madhan, Rajesh, Sudhakar, and Sunil. Approvals were obtained from the University of California, Davis, Institutional Animal Care and Use Committee, to comply with animal-welfare regulations under Protocol numbers 13378 and 15667.

\section{References}

Andheria, A.P., Karanth, K.U. \& Kumar, N.S. (2007) Diet and prey profiles of three sympatric large carnivores in Bandipur Tiger Reserve, India. Journal of Zoology, 273, 169-175.

BANDARA, R. \& Tisdell, C. (2003) Comparison of rural and urban attitudes to the conservation of Asian elephants in Sri Lanka: empirical evidence. Biological Conservation, 110, 327-342.

Chauhan, P.R. (2008) Large mammal fossil occurrences and associated archaeological evidence in Pleistocene contexts of peninsular India and Sri Lanka. Quaternary International, 192, 20-42.

Chiyo, P.I. \& Cochrane, E.P. (2005) Population structure and behaviour of crop-raiding elephants in Kibale National Park, Uganda. African Journal of Ecology, 43, 233-241.

Dukes, W.F. (1965) N=1. Psychological Bulletin, 64, 74-79.

Gubis, S. (2009) Elephant deaths due to electrocution: a consequence of inappropriate habitat management? Oryx, 43, 326-327.

Gunn, J., Hawkins, D., Barnes, R.F.W., Mofulu, F., Grant, R.A. \& Norton, G.W. (2014) The influence of lunar cycles on crop-raiding elephants: evidence for risk avoidance. African Journal of Ecology, 52, 129-137.

Hayward, M.W., Henschel, P., O’Brien, J., Hofmeyr, M., Balme, G. \& Kerley, G.I.H. (2006) Prey preferences of the leopard (Panthera pardus). Journal of Zoology, 270, 298-313.

King, L.E., Lawrence, A., Douglas-Hamilton, I. \& Vollrath, F. (2009) Beehive fence deters crop-raiding elephants. African Journal of Ecology, 47, 131-137.

Kumaraguru, A., Saravanamuthu, R., Brinda, K. \& Asokan, S. (2011) Prey preference of large carnivores in Anamalai Tiger Reserve, India. European Journal of Wildlife Research, 57, 627-637.

MADHUSUdAN, M.D. (2003) Living amidst large wildlife: livestock and crop depredation by large mammals in the interior villages of Bhadra Tiger Reserve, South India. Environmental Management, 31 , 466-475.

Manamendra-Arachchi, K., Pethiyagoda, R., Dissanayake, R. \& Meegaskumbura, M. (2005) A second extinct big cat from the Late Quarternary of Sri Lanka. Raffles Bulletin of Zoology Supplement, 12, 423-434.
McComb, K., Packer, C. \& Pusey, A. (1994) Roaring and numerical assessment in contests between groups of female lions, Panthera leo. Animal Behaviour, 47, 379-387.

McComb, K., Shannon, G., Durant, S. M., Sayialel, K., Slotow, R., Poole, J. \& Moss, C. (2011) Leadership in elephants: the adaptive value of age. Proceedings of the Royal Society B, 278, 3270-3276.

Osborn, F.V. (2004) Seasonal variation of feeding patterns and food selection by crop-raiding elephants in Zimbabwe. African Journal of Ecology, 42, 322-327.

Power, R.J. \& Compion, R.X.S. (2009) Lion predation on elephants in the Savuti, Chobe National Park, Botswana. African Zoology, 44, $36-44$.

Rangarajan, M., Desai, A., Sukumar, R., Easa, P.S., Menon, V., VInCEnt, S. et al. (2010) Gajah: Securing the Future for Elephants in India. The Report of the Elephant Task Force. Ministry of Environment and Forests, Government of India, New Delhi, India.

Rode, K.D., Chiyo, P.I., Chapman, C.A. \& McDowell, L.R. (2006) Nutritional ecology of elephants in Kibale National Park, Uganda, and its relationship with crop-raiding behaviour. Journal of Tropical Ecology, 22, 441-449.

Silori, C.S. \& Mishra, B.K. (2001) Assessment of livestock grazing pressure in and around the elephant corridors in Mudumalai Wildlife Sanctuary, south India. Biodiversity and Conservation, 10, 2181-2195.

Sitati, N.W., Walpole, M.J. \& Leader-Williams, N. (2005) Factors affecting susceptibility of farms to crop-raiding by African elephants: using a predictive model to mitigate conflict. Journal of Applied Ecology, 42, 1175-1182.

Sukumar, R. (1990) Ecology of the Asian elephant in southern India. II. Feeding habits and crop-raiding patterns. Journal of Tropical Ecology, 6, 33-53.

Sukumar, R. (2003) The Living Elephants: Evolutionary Ecology, Behavior, and Conservation. Oxford University Press, New York, USA.

Sukumar, R. \& Santiapillai, C. (1996) Elephas maximus: status and distribution. In The Proboscidea: Evolution and Palaeoecology of Elephants and their Relatives (eds J. Shoshani \& P. Tassy), pp. 327-331. Oxford University Press, New York, USA.

ThuppiL, V. \& Coss, R.G. (2012) Using threatening sounds as a conservation tool: evolutionary bases for better managing humanelephant conflict in India within the existing legal framework. Journal of International Wildlife Law and Policy, 15, 167-185.

Thuppil, V. \& Coss, R.G. (2013) Wild Asian elephants distinguish aggressive tiger and leopard growls according to perceived danger. Biology Letters, 9, 20130518.

Tseng, Z.J., Wang, X., Slater, G.J., Takeuchi, G.T., Li, Q., Lui, J. \& XIE, G. (2013) Himalayan fossils of the oldest known pantherine establish ancient origin of big cats. Proceedings of the Royal Society $B, 281,20132686$.

\section{Biographical sketches}

VIVEK THUPPIL is a psychologist interested in exploring the interface of basic research and applied wildlife conservation. In particular, he is interested in animal behaviour and cognition research for the mitigation of human-wildlife conflict. RICH A R D Coss is a psychologist interested in studying evolutionary constraints on perceptual and cognitive processes in different species. He is particularly interested in examining population differences, predator-prey interactions, habitat perception, and social communication. 